TechnoLEARN: An International Journal of Educational Technology

TechnoLEARN: 9(2): 59-70, December 2019

DOI: $10.30954 / 2231-4105.02 .2019 .1$

(C2019 New Delhi Publishers. All rights reserved

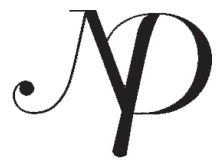

\title{
Effect of Deprivation on Social Behaviours
}

\author{
K.S. Misra \\ Former Vice Chancellor (O), University of Allahabad, Prayagraj-211002, India \\ Corresponding author: ksmisra1955@yahoo.co.in
}

\begin{abstract}
Deprivation indicates lack of opportunities to have experiences that are available to the majority of children. It can adversely affect the social functioning of students among boys and girls. It was hypothesized that deprivation in various areas can predict variances in social behaviours of boys and girls differently. Social Behaviour Questionnaire of S.K. Pal, K.S. Misra and M. Gupta and Deprivaion Scale of S.K. Pal, K. Pandey and K.S. Misra were used to collect data. Correlation, t-ratio and regression analysis were used to analyze the data. Results revealed that girls exhibit more concern for others but less social passivity; deprivation in all the eight areas, viz. physiological, fulfillment of needs, ecological, social, emotional, economic, educational and parental areas is positively related to social passivity among boys; tolerance is not related to any area of deprivation as perceived by boys as well as girls; dependence, power assertion, ingratiation and social conversation among boys and girls are positively related to physiological, ecological, emotional and economic deprivations; all the eight areas of deprivation contribute to more than ten per cent variance in boys' compliance, dependence, ingratiation, social conversation, social passivity, aggression and withdrawal, and girl's power assertion, ingratiation, social passivity, aggression and withdrawal; concern for others and tolerance among boys are the two least affected social behaviours among boys while in the case of girls concern for others, compliance and social conversation are the three least affected social behaviours.
\end{abstract}

Keywords: Social behaviours, questionnaire, social, emotional, economic, educational

Deprivation refers to a felt loss or deficiencies- actual or perceived, in the environment. It results from withdrawal or taking away of a thing from a person which should have been normally possessed by him. It also denotes lack of opportunities to have experiences. It can be absolute or relative, short term or prolonged, intense or mild, full or partial. Misra and Tripathi (1987) concluded that the term 'deprivation' has been used to denote deficient environmental conditions and impoverished experiences. They measured deprivation in fifteen areas- housing condition, home environment, economic sufficiency, food, clothing, formal educational 
p

experiences, childhood experiences, reading experiences, parental characteristics, interaction with parents, motivational experiences, emotional experiences, emotional experiences, religious experiences, travel and recreation, and miscellaneous quasi-cultural experience. Pandey (1987) talked about social, educational, emotional, economic and parental deprivation. Pal and Misra (1991) added ecological, physiological and need deprivation to the list. Education of the disadvantaged sections of the society has always remained a challenge for policy makers in India. Only a few highly deprived persons have been in a position to offset the ill effects of short or prolonged deprivation. Feelings of deprivation can make students incapable of effective participation in society. The present study has been done to find out how different kinds of deprivations influence the social behaviours of boys and girls.

\section{Objectives of the Study}

The objectives of the study are as follows:

1. To compare boys and girls on social behaviours.

2. To find out the relationship between different types of deprivation and social behaviours among boys and girls.

3. To find out the contribution of different types of deprivation to various social behaviours.

\section{Research Hypotheses}

The following research hypotheses were formulated:

1. Boys differ from girls on social behaviours.

2. Different types of deprivation and social behaviours among boys and girls are differently related.

3. Diifferent types of deprivation contribute differently to variance in social behaviours.

\section{Method of Study}

Sample: The sample for the study consisted of 525 students (253 boys and 272 girls) studying in14 schools of Prayagraj city.

Tools used: Following tools were used to collect the data:

1. 'Deprivation Scale' constructed by S.K. Pal, Kalplata Pandey and K.S. Misra

2. 'Need Fulfilment Scale', 'Physiological Depriavation Scale' and Ecological Deprivation Scale' constructed by S.K. Pal and K.S. Misra.

3. 'Social Behaviour Questionnaire' constructed by S.K.Pal, K.S. Misra and Meenu Gupta 
Statistics used: t-ratios, Product moment correlations, and multiple correlations have been used.

\section{RESULTS AND DISCUSSION}

Table 1: Mean, standard deviations and t-ratios showing differences between boys and girls students on social behaviours

\begin{tabular}{ccccccc}
\hline \multirow{2}{*}{ S1. No. } & \multirow{2}{*}{ Social behaviour } & \multicolumn{2}{c}{ Mean } & \multicolumn{2}{c}{ Standard deviation } & \multirow{2}{*}{ t-ratio } \\
\cline { 3 - 5 } & & Boys & Girls & Boys & Girls & \\
\hline 1 & Concern for others & 10.1691 & 11.1261 & 1.5298 & 1.6076 & $6.9752^{* *}$ \\
2 & Compliance & 7.2206 & 7.1344 & 2.4711 & 2.2515 & 0.4182 \\
3 & Dependence & 7.3015 & 7.1739 & 2.1019 & 2.1085 & 0.6939 \\
4 & Power assertion & 5.5735 & 5.6087 & 2.5343 & 2.2993 & 0.2290 \\
5 & Ingratiation & 6.2721 & 6.2451 & 2.5671 & 2.1775 & 0.1302 \\
6 & Social conversation & 8.0184 & 8.2016 & 2.1943 & 2.0632 & 0.9860 \\
7 & Social passivity & 2.8529 & 2.5415 & 2.3606 & 2.2243 & $0 . .5562$ \\
8 & Aggression & 4.02735 & 3.4229 & 2.5776 & 2.2746 & $3.0718^{* *}$ \\
9 & Withdrawal & 4.0993 & 3.8617 & 2.2585 & 2.1196 & 1.2433 \\
10 & Tolerance & 7.4706 & 7.3557 & 2.6602 & 2.5681 & 0.5035 \\
\hline
\end{tabular}

** Significant at .01 level.

It was hypothesized that boys do not significantly differ from girls on social behaviours. A look at table 1 shows that girls exhibit more concern for others $(t=.6 .9752, p<.01)$ but less social passivity $(t=3.0718, \mathrm{p}<.01)$. Other eight $\mathrm{t}$-ratios are not significant at .05 level. It shows that boys do not differ from girls on compliance $(t=0.4182)$, dependence $(t=0.6939)$, power assertion $(t=0.2290)$, ingratiation $(t=0.1302)$, social conversation $(t=0.9860)$, aggression $(t=$ $0.1 .5562)$, withdrawal $(t=1.2433)$, tolerance $(t=0.5035)$.

Table 2: Correlations and R-square changes showing various kinds of deprivation as predictors of concern for others among boys and girls

\begin{tabular}{cccccc}
\hline \multirow{2}{*}{$\begin{array}{c}\text { S1. } \\
\text { No. }\end{array}$} & Kind of & \multicolumn{2}{c}{ For boys } & \multicolumn{2}{c}{ For girls } \\
\cline { 3 - 6 } deprivation & Correlation & R- square change & Correlation & R- square change \\
\hline 1 & Physiological & -.088 & .779 & -.0552 & .304 \\
2 & Ecological & .049 & 1.605 & -.0868 & .450 \\
3 & Nonfulfilment of & -.063 & .307 & -.0797 & .336 \\
& needs & & & & 1.647
\end{tabular}


\%

Misra

\begin{tabular}{|c|c|c|c|c|c|}
\hline 5 & Emotional & .061 & 1.287 & $-.1268^{*}$ & .106 \\
\hline 6 & Economic & .077 & .744 & $-.1578^{* *}$ & .556 \\
\hline 7 & Educational & -.000 & .278 & $-.1522^{* *}$ & .149 \\
\hline 8 & Parental & -.039 & .525 & $-.1369^{*}$ & .165 \\
\hline 9 & Multiple R & \multicolumn{2}{|c|}{.2353} & \multicolumn{2}{|c|}{.1927} \\
\hline 10 & R square & \multicolumn{2}{|c|}{.0554} & \multicolumn{2}{|c|}{.0371} \\
\hline
\end{tabular}

*/** significant at .05/.01 level.

Table 2 shows that all the eight deprivation viz.- physiological, ecological, non-fulfillment of needs, social, emotional, economic, educational and parental, are not significantly related to concern for others among boys. Taken together these deprivations contribute to 5.54 per cent variance in boys' scores on concern for others $(\mathrm{R}=.2353, \mathrm{R}$ square $=.0554)$. Highest contribution is made by ' ecological deprivation' $(\mathrm{R}$ square change $=1.605$ ) and the next major contributors is 'emotional deprivation' $(R$ square change $=1.287)$. In the case of girls five deprivations viz.- social, emotional, economic, educational and parental, are negatively related to concern for others. Physiological, ecological and non-fulfillment of needs are not significantly related to concern for others. Taken together all the eight deprivations contribute to 3.71 per cent variance in girls' scores on concern for others $(R=.1927$, $R$ square $=.0371)$. Highest contribution is made by 'social deprivation' ( $R$ square change $=1.647$ ) and the next major contributors is 'economic deprivation' ( $\mathrm{R}$ square change $=0.556$ ).

Table 3: Correlations and R-square changes showing various kinds of deprivation as predictors of compliance among boys and girls

\begin{tabular}{cccccc}
\hline \multirow{2}{*}{ S1. No. } & Kind of & \multicolumn{2}{c}{ For boys } & \multicolumn{2}{c}{ For girls } \\
\cline { 3 - 6 } & deprivation & Correlation & R- square change & Correlation & R- square change \\
\hline 1 & Physiological & $.1999^{* *}$ & 3.995 & $.1278^{*}$ & 1.633 \\
2 & Ecological & $.2129^{* *}$ & 1.359 & $.1860^{* *}$ & 1.852 \\
3 & Nonfulfilment of & -.0460 & 1.223 & .0422 & .014 \\
& needs & & & & .564 \\
4 & Social & .1189 & .203 & $.1369^{*}$ & .178 \\
5 & Emotional & $.2332^{* *}$ & 1.787 & .0869 & .081 \\
6 & Economic & $.2575^{* *}$ & 1.613 & $.1325^{*}$ & .014 \\
7 & Educational & .1160 & .610 & .0905 & .193 \\
8 & Parental & .0938 & .494 & $.1148^{*}$ & .2128 \\
9 & Multiple R & & .3359 & & .0453 \\
10 & R square & & .1128 & & \\
\hline
\end{tabular}

*/** significant at .05/.01 level. 
Table 3 shows that deprivation in physiological, ecological, emotional and economic areas is positively related to compliance while deprivation in fulfillment of needs, social, educational and parental is not significantly related to compliance among boys. Taken together the eight areas of deprivation contribute to 11.28 per cent variance in boys' scores on compliance $(\mathrm{R}=$ .3359, R square = .1128). Highest contribution is made by 'physiological deprivation' ( $R$ square change $=3.995$ ) and the next major contributor is 'emotional deprivation' ( $R$ square change = 1.787). In the case of girls five deprivations viz.- physiological, social, ecological, economic and parental, are positively related to compliance. Non-fulfillment of needs, emotional and educational deprivations are not significantly related to compliance. Taken together all the eight deprivations contribute to 4.53 per cent variance in girls' scores on concern for others $(\mathrm{R}=.2128$, $\mathrm{R}$ square $=.0453)$. Highest contribution is made by 'ecological deprivation' ( $\mathrm{R}$ square change $=1.852$ ) and the next major contributor is 'physiological deprivation' ( $R$ square change $=1.633$ ).

Table 4: Correlations and R-square changes showing various kinds of deprivation as predictors of dependence among boys and girls

\begin{tabular}{|c|c|c|c|c|c|}
\hline \multirow{2}{*}{$\begin{array}{l}\text { Sl. } \\
\text { No. }\end{array}$} & \multirow{2}{*}{$\begin{array}{c}\text { Kind of } \\
\text { deprivation }\end{array}$} & \multicolumn{2}{|c|}{ For boys } & \multicolumn{2}{|c|}{ For girls } \\
\hline & & Correlation & R-square change & Correlation & R-square change \\
\hline 1 & Physiological & $.2297^{* *}$ & 5.277 & $.1520^{* *}$ & 2.311 \\
\hline 2 & Ecological & $.1831^{* *}$ & .328 & $.1751^{* *}$ & 1.061 \\
\hline 3 & $\begin{array}{l}\text { Nonfulfilment of } \\
\text { needs }\end{array}$ & .1350 & .567 & -.0194 & .605 \\
\hline 4 & Social & .0738 & .000 & $.1363^{* *}$ & .588 \\
\hline 5 & Emotional & $.2500^{* *}$ & 4.707 & $.2215^{* *}$ & 1.967 \\
\hline 6 & Economic & $.2995^{* *}$ & 3.664 & $.2625^{* *}$ & 1.853 \\
\hline 7 & Educational & .1278 & .224 & $.2097^{* *}$ & .013 \\
\hline 8 & Parental & .0632 & 1.133 & $.2381^{* *}$ & .734 \\
\hline 9 & Multiple R & \multicolumn{2}{|c|}{.3987} & \multicolumn{2}{|c|}{.3022} \\
\hline 10 & R square & \multicolumn{2}{|c|}{.159} & \multicolumn{2}{|c|}{.0913} \\
\hline
\end{tabular}

**** significant at $.05 / .01$ level.

Table 4 shows that deprivation in physiological, ecological, emotional and economic areas is positively related to dependence while deprivation in fulfillment of needs, social, educational and parental is not significantly related to dependence among boys. Taken together the eight areas of deprivation contribute to 15.9 per cent variance in boys' scores on dependence ( $R=$ .3987 , R square = .159). Highest contribution is made by 'physiological deprivation' (R square change $=5.277$ ) and the next major contributor is 'emotional deprivation' ( $\mathrm{R}$ square change= 4.707). In the case of girls seven deprivations viz.- physiological, social, emotional, ecological, 
P Misra

economic, educational and parental, are positively related to dependence. Non-fulfillment of needs is not significantly related to dependence. Taken together all the eight deprivations contribute to 4.53 per cent variance in girls' scores on dependence $(R=.3032$, $R$ square $=.0913)$. Highest contribution is made by 'physiological deprivation' $(R$ square change $=2.311)$ and the next major contributor is 'emotional deprivation' ( $\mathrm{R}$ square change $=1.967$ ).

Table 5: Correlations and R-square changes showing various kinds of deprivation as predictors of power assertion among boys and girls

\begin{tabular}{cccccc}
\hline \multirow{2}{*}{$\begin{array}{c}\text { S1. } \\
\text { No. }\end{array}$} & Kind of & \multicolumn{2}{c}{ For boys } & \multicolumn{2}{c}{ For girls } \\
\cline { 2 - 6 } deprivation & Correlation & R-square change & Correlation & R-square change \\
\hline 1 & Physiological & $.191^{* *}$ & 3.647 & $.2272^{* *}$ & 5.164 \\
2 & Ecological & $.1688^{* *}$ & .465 & $.2190^{* *}$ & .987 \\
3 & Nonfulfilment of & .0519 & .000 & .0918 & .036 \\
& needs & & & & \\
4 & Social & .1203 & .347 & $.1924^{* *}$ & .035 \\
5 & Emotional & $.2584^{* *}$ & 3.719 & $.2182^{* *}$ & .570 \\
6 & Economic & $.2338^{* *}$ & .612 & $.2851^{* *}$ & 2.160 \\
7 & Educational & $.1535^{*}$ & .031 & $.2480^{* *}$ & .343 \\
8 & Parental & $.1515^{*}$ & .004 & $.2512^{* *}$ & .790 \\
9 & Multiple R & & .2971 & & .3329 \\
10 & R square & & .0883 & & .1108 \\
\hline
\end{tabular}

**** significant at .05/.01 level.

Table 5 shows that deprivation in physiological, ecological, emotional, economic, educational and parental areas is positively related to power assertion while deprivation in fulfillment of needs, social, is not significantly related to power assertion among boys. Taken together the eight areas of deprivation contribute to 8.83 per cent variance in boys' scores on power assertion $(\mathrm{R}=.2971, \mathrm{R}$ square $=.0883)$. Highest contribution is made by 'emotional deprivation' $(\mathrm{R}$ square change $=3.719$ ) and the next major contributor is 'physiological deprivation' ( $R$ square change $=3.647$ ). In the case of girls seven deprivations viz.- physiological, social, emotional, ecological, economic, educational and parental, are positively related to power assertion. Non-fulfillment of needs is not significantly related to power assertion. Taken together all the eight deprivations contribute to 11.08 per cent variance in girls' scores on power assertion $(\mathrm{R}=.3329 \mathrm{R}$ square $=.1108)$. Highest contribution is made by 'physiological deprivation' ( $\mathrm{R}$ square change $=5.164)$ and the next major contributor is 'emotional deprivation' ( $\mathrm{R}$ square change $=2.160$ ). 
Table 6: Correlations and R-square changes showing various kinds of deprivation as predictors of ingratiation among boys and girls

\begin{tabular}{|c|c|c|c|c|c|}
\hline \multirow{2}{*}{ Sl. No. } & \multirow{2}{*}{$\begin{array}{c}\text { Kind of } \\
\text { deprivation }\end{array}$} & \multicolumn{2}{|c|}{ For boys } & \multicolumn{2}{|c|}{ For girls } \\
\hline & & Correlation & R-square change & Correlation & R-square change \\
\hline 1 & Physiological & $.3347^{* *}$ & 11.202 & $.1819^{* *}$ & 3.308 \\
\hline 2 & Ecological & $.3367^{* *}$ & 2.9111 & $.2802^{* *}$ & 4.552 \\
\hline 3 & $\begin{array}{c}\text { Nonfulfilment of } \\
\text { needs }\end{array}$ & .0899 & .009 & $.1094^{*}$ & .100 \\
\hline 4 & Social & $.1957^{* *}$ & .632 & $1952^{* *}$ & .996 \\
\hline 5 & Emotional & $.3477^{* *}$ & 3.610 & $.1465^{* *}$ & .123 \\
\hline 6 & Economic & $.3618^{* *}$ & 1.762 & $.2660^{* *}$ & 1.792 \\
\hline 7 & Educational & $.2643^{* *}$ & .093 & $.2475^{* *}$ & 1.238 \\
\hline 8 & Parental & $.2001^{* *}$ & .1380 & $.1515^{*}$ & .039 \\
\hline 9 & Multiple R & \multicolumn{2}{|c|}{.4512} & \multicolumn{2}{|c|}{.3485} \\
\hline 10 & R square & \multicolumn{2}{|c|}{2036} & \multicolumn{2}{|c|}{.1215} \\
\hline
\end{tabular}

*/** significant at .05/.01 level.

Table 6 shows that deprivation in physiological, ecological, social, emotional, economic, educational and parental areas is positively related to ingratiation while deprivation in fulfillment of needs is not significantly related to ingratiation among boys. Taken together the eight areas of deprivation contribute to 20.36 per cent variance in boys' scores on ingratiation $(\mathrm{R}=.4512$, $\mathrm{R}$ square $=.2036)$. Highest contribution is made by 'physiological deprivation' ( $\mathrm{R}$ square change $=11.202$ ) and the next major contributor is 'emotional deprivation' ( $R$ square change $=3.610$ ). In the case of girls all the eight deprivations viz.- physiological, fulfillment of needs, social, emotional, ecological, economic, educational and parental, are positively related to ingratiation. Taken together all the eight deprivations contribute to 12.15 per cent variance in girls' scores on of ingratiation $(\mathrm{R}=.3485 \mathrm{R}$ square $=.1215)$. Highest contribution is made by 'ecological deprivation' ( $\mathrm{R}$ square change $=4.552$ ) and the next major contributor is 'physiological deprivation' ( $\mathrm{R}$ square change $=3.308$ ).

Table 7: Correlations and R-square changes showing various kinds of deprivation as predictors of social conversation among boys and girls

\begin{tabular}{cccccc}
\hline \multirow{2}{*}{ S1. No. } & \multirow{2}{*}{ Kind of deprivation } & \multicolumn{2}{c}{ For boys } & \multicolumn{2}{c}{ For girls } \\
\cline { 3 - 6 } & & Correlation & R-square change & Correlation & R-square change \\
\hline 1 & Physiological & $.2091^{* *}$ & 4.374 & .0924 & .854 \\
2 & Ecological & $.2193^{* *}$ & 1.385 & $.1496^{* *}$ & 1.383 \\
3 & Nonfulfilment of needs & -.0289 & .908 & .0032 & .162
\end{tabular}


\%

Misra

\begin{tabular}{|c|c|c|c|c|c|}
\hline 4 & Social & .0128 & .485 & .1030 & .332 \\
\hline 5 & Emotional & $.2773^{* *}$ & 8.255 & .0910 & .000 \\
\hline 6 & Economic & $.2089^{* *}$ & .420 & $.1636^{* *}$ & .873 \\
\hline 7 & Educational & $.1603^{*}$ & .054 & $.1092^{*}$ & .000 \\
\hline 8 & Parental & .01795 & .322 & .0667 & .130 \\
\hline 9 & Multiple R & \multicolumn{2}{|c|}{.4025} & \multicolumn{2}{|c|}{.1933} \\
\hline 10 & R square & \multicolumn{2}{|c|}{.1620} & \multicolumn{2}{|c|}{.0374} \\
\hline
\end{tabular}

*** significant at $.05 / .01$ level.

Table 7 shows that deprivation in physiological, ecological, emotional, economic, educational areas is positively related to social conversation while deprivation in fulfillment of needs, social and parental is not significantly related to social conversation among boys. Taken together the eight areas of deprivation contribute to 16.20 per cent variance in boys' scores on social conversation $(\mathrm{R}=.4025$, $\mathrm{R}$ square $=.1620)$. Highest contribution is made by 'emotional deprivation' ( $R$ square change $=8.255$ ) and the next major contributor is 'physiological deprivation' ( $\mathrm{R}$ square change $=4.374$ ). In the case of girls ecological, economic and educational deprivations are positively related to social conversation while deprivations in physiological, fulfillment of needs, social, emotional, and parental, are not significantly related to social conversation Taken together all the eight deprivations contribute to 3.74 per cent variance in girls' scores on of social conversation $(R=.1934 \mathrm{R}$ square $=.0374)$. Highest contribution is made by 'ecological deprivation' ( $\mathrm{R}$ square change $=4.552$ ) and the next major contributor is 'economic deprivation' ( $\mathrm{R}$ square change $=.873$ ).

Table 8: Correlations and R-square changes showing various kinds of deprivation as predictors of social passivity among boys and girls

\begin{tabular}{cccccc}
\hline \multirow{2}{*}{ S1. No. } & \multirow{2}{*}{ Kind of deprivation } & \multicolumn{2}{c}{ For boys } & \multicolumn{2}{c}{ For girls } \\
\cline { 3 - 6 } & & Correlation & R-square change & Correlation & R- square change \\
\hline 1 & Physiological & $.3255^{* *}$ & 10.595 & $.1550^{* *}$ & 2.403 \\
2 & Ecological & $.2062^{* *}$ & .022 & $.2678^{* *}$ & 4.789 \\
3 & Nonfulfilment of needs & $.2041^{* *}$ & 1.599 & $.1336^{*}$ & .402 \\
4 & Social & $.2243^{* *}$ & 1.932 & $.2621^{* *}$ & 3.229 \\
5 & Emotional & $.36555^{* *}$ & 5.389 & $.3886^{* *}$ & 6.132 \\
6 & Economic & $.2868^{* *}$ & .025 & $.3909^{* *}$ & 1.936 \\
7 & Educational & $.2482^{* *}$ & .092 & $.3439^{* *}$ & 001 \\
8 & Parental & $.1571^{*}$ & .578 & $.3444^{* *}$ & .847 \\
9 & Multiple R & \multicolumn{2}{c}{.4498} & & .4443 \\
10 & R square & \multicolumn{2}{c}{.2023} & & .1974 \\
\hline
\end{tabular}

*/** significant at .05/.01 level. 
Table 8 shows that deprivation in all the eight areas, viz. physiological, fulfillment of needs, ecological, social, emotional, economic, educational and parental areas is positively related to social passivity among boys. Taken together the eight areas of deprivation contribute to 20.23 per cent variance in boys' scores on social passivity $(\mathrm{R}=.4498, \mathrm{R}$ square $=.2023)$. Highest contribution is made by 'physiological deprivation' ( $R$ square change $=10.595$ and the next major contributor is 'emotional deprivation'( $\mathrm{R}$ square change $=5.389)$. In the case of girls all the eight deprivations viz.- physiological, fulfillment of needs, social, emotional, ecological, economic, educational and parental, are positively related to social passivity. Taken together all the eight deprivations contribute to 19.74 per cent variance in girls' scores on of social passivity $(\mathrm{R}=.4443, \mathrm{R}$ square $=.1974)$. Highest contribution is made by 'emotional deprivation' ( $\mathrm{R}$ square change $=6.132$ ) and the next major contributor is 'ecological deprivation' ( $\mathrm{R}$ square change $=4.789$ ).

Table 9: Correlations and R-square changes showing various kinds of deprivation as predictors of aggression among boys and girls

\begin{tabular}{|c|c|c|c|c|c|}
\hline \multirow{2}{*}{ S1. No. } & \multirow{2}{*}{ Kind of deprivation } & \multicolumn{2}{|c|}{ For boys } & \multicolumn{2}{|c|}{ For girls } \\
\hline & & Correlation & R-square change & Correlation & R-square change \\
\hline 1 & Physiological & $.3480^{* *}$ & 12.111 & $.2255^{* *}$ & 5.084 \\
\hline 2 & Ecological & $.2685^{* *}$ & .571 & $.2062^{* *}$ & .714 \\
\hline 3 & $\begin{array}{l}\text { Nonfulfilment of } \\
\text { needs }\end{array}$ & $.1575^{*}$ & .441 & .0835 & .017 \\
\hline 4 & Social & $.2421^{* *}$ & 1.973 & $.2184^{* *}$ & 1.795 \\
\hline 5 & Emotional & $.3355^{* *}$ & 2.225 & $.2962^{* *}$ & 2.740 \\
\hline 6 & Economic & $.3432^{* *}$ & 1.037 & $.2889^{* *}$ & .957 \\
\hline 7 & Educational & $.2565^{* *}$ & .049 & $.2143^{* *}$ & .356 \\
\hline 8 & Parental & $.2130^{* *}$ & .057 & $.2541^{* *}$ & .590 \\
\hline 9 & Multiple R & \multicolumn{2}{|c|}{.4297} & \multicolumn{2}{|c|}{.3501} \\
\hline 10 & R square & \multicolumn{2}{|c|}{.1846} & \multicolumn{2}{|c|}{.1225} \\
\hline
\end{tabular}

*/** significant at .05/.01 level.

Table 9 shows that deprivation in all the eight areas is positively related to aggression. Taken together the eight areas of deprivation contribute to 18.46 per cent variance in boys' scores on aggression $(\mathrm{R}=.4297$, $\mathrm{R}$ square $=.1846)$. Highest contribution is made by 'physiological deprivation' ( $\mathrm{R}$ square change $=12.111$ ) and the next major contributor is 'emotional deprivation' ( $\mathrm{R}$ square change $=2.225)$. In the case of girls seven areas of deprivations viz.physiological, social, emotional, ecological, economic, educational and parental, are positively related to aggression while non-fulfillment of needs is not significantly related to aggression. 
p

Misra

Taken together all the eight deprivations contribute to 12.25 per cent variance in girls' scores on of aggression $(\mathrm{R}=.3501 \mathrm{R}$ square $=.1225)$. Highest contribution is made by 'physiological deprivation' ( $R$ square change $=5.084)$ and the next major contributor is 'emotional deprivation' $(\mathrm{R}$ square change $=2.740)$.

Table 10: Correlations and R-square changes showing various kinds of deprivation as predictors of withdrawal among boys and girls

\begin{tabular}{|c|c|c|c|c|c|}
\hline \multirow{2}{*}{ S1. No. } & \multirow{2}{*}{ Kind of deprivation } & \multicolumn{2}{|c|}{ For boys } & \multicolumn{2}{|c|}{ For girls } \\
\hline & & Correlation & R-square change & Correlation & R-square change \\
\hline 1 & Physiological & $.3154^{* *}$ & 9.948 & $.1638^{* *}$ & 2.684 \\
\hline 2 & Ecological & $.2095^{* *}$ & .069 & $.1839^{* *}$ & 1.098 \\
\hline 3 & $\begin{array}{l}\text { Nonfulfilment of } \\
\text { needs }\end{array}$ & .0061 & 600 & .0986 & .180 \\
\hline 4 & Social & $.2677^{* *}$ & 3.294 & $.2349^{* *}$ & 2.882 \\
\hline 5 & Emotional & $.3888^{* *}$ & 4.198 & $.3219^{* *}$ & 3.990 \\
\hline 6 & Economic & $.3173^{* *}$ & .152 & $.3222^{* *}$ & 1.689 \\
\hline 7 & Educational & $.2870^{* *}$ & .079 & $.3076^{* *}$ & .216 \\
\hline 8 & Parental & $1609^{*}$ & 1.104 & $.2558^{* *}$ & .091 \\
\hline 9 & Multiple R & \multicolumn{2}{|c|}{. .441} & \multicolumn{2}{|c|}{.3582} \\
\hline 10 & R square & \multicolumn{2}{|c|}{.1945} & \multicolumn{2}{|c|}{.1283} \\
\hline
\end{tabular}

*/** significant at .05/.01 level.

Table 10 shows that deprivation in physiological, ecological, social, emotional, economic, educational and parental areas is positively related to withdrawal while deprivation in fulfillment of needs is not significantly related to withdrawal among boys. Taken together the eight areas of deprivation contribute to 19.45 per cent variance in boys' scores on withdrawal $(\mathrm{R}=.441, \mathrm{R}$ square $=.1945)$. Highest contribution is made by 'physiological deprivation' ( $\mathrm{R}$ square change $==9.948$ ) and the next major contributor is 'emotional deprivation' ( $R$ square change $=4.198$ ). In the case of girls too the seven deprivations viz.- physiological, social, emotional, ecological, economic, educational and parental, are positively related to withdrawal. Taken together all the eight deprivations contribute to 12.83 per cent variance in girls' scores on of withdrawal $(\mathrm{R}=.3582 \mathrm{R}$ square $=.1283)$. Highest contribution is made by 'emotional deprivation' ( $R$ square change $=3.990$ ) and the next major contributor is 'physiological deprivation' ( $\mathrm{R}$ square change $=2.684)$. 
Table 11: Correlations and R-square changes showing various kinds of deprivation as predictors of tolerance among boys and girls

\begin{tabular}{cccccc}
\hline \multirow{2}{*}{ S1. No. } & \multirow{2}{*}{ Kind of deprivation } & \multicolumn{2}{c}{ For boys } & \multicolumn{3}{c}{ For girls } \\
\cline { 3 - 6 } & & Correlation & R-square change & Correlation & R-square change \\
\hline 1 & Physiological & .0799 & .639 & -.0132 & .017 \\
2 & Ecological & .0652 & .047 & .0377 & .343 \\
3 & Nonfulfilment of needs & .0495 & .082 & -.0621 & .501 \\
4 & Social & -.0319 & .366 & -.0224 & .061 \\
5 & Emotional & .1157 & 2.786 & -.0699 & .731 \\
6 & Economic & .0798 & .115 & -.0082 & .045 \\
7 & Educational & -.0368 & 1.312 & -.0440 & .024 \\
8 & Parental & -.0302 & .612 & -.0377 & .028 \\
9 & Multiple R & \multicolumn{2}{c}{.2441} & & .1323 \\
10 & R square & .0596 & & .0175 \\
\hline
\end{tabular}

**** significant at $.05 / .01$ level.

Table 11 shows that deprivation in all the eight areas viz., physiological, fulfillment of needs, ecological, social, emotional, economic, educational and parental areas is not significantly related to tolerance. Taken together the eight areas of deprivation contribute to 5.96 per cent variance in boys' scores tolerance $(\mathrm{R}=.2441, \mathrm{R}$ square $=.0596)$. Highest contribution is made by 'emotional, deprivation' ( $R$ square change $=2.786$ ) and the next major contributor is 'educational deprivation' ( $\mathrm{R}$ square change $=1.312$ ). In the case of girls too all the eight deprivations are not significantly related to tolerance. Taken together all the eight deprivations contribute to 1.751 per cent variance in girls' scores on tolerance $(R=.1323$, $R$ square $=.0175)$. Highest contribution is made by 'emotional deprivation' ( $\mathrm{R}$ square change $=.731$ ) and the next major contributor is 'deprivation in fulfillment of needs' ( $R$ square change $=.501$ ).

Tolerance has not been found to be related to any area of deprivation as perceived by boys as well as girls. It seems that exposure to diverse kinds of deprivations might have compelled boys as well as girls to raise their voice against deprivation and this might have led to development of low tolerance among them. Concern for others is not related to any area of deprivation among boys but for girls it is negatively related to social, emotional, economic, educational and parental areas of deprivation. This shows that concern for others among girls is more adversely affected by deprivation as compared to boys. Social passivity, withdrawal and aggression are positively related to physiological, ecological, social, emotional, economic, educational and parental deprivations. Non-fulfillment of needs is positively related to Social passivity and aggression among boys but for girls the relationship is not significant. Nonfulfillment of needs is positively related to aggression among boys and withdrawal among 
p

girls. Dependence, power assertion, ingratiation and social conversation among boys and girls are positively related to physiological, ecological, motional and economic deprivations. It means that exposure to these deprivations increase dependence of deprived students on others who can easily be seen as most potent factors to reduce the ill effects of deprivation. Conditions of life make them assert their power to demand their rights- human as well as those fundamental rights guaranteed by the Indian Constitution. As a corollary the deprived will try to develop their competence of social conversation and tendency for impression management. 'Ingratiation" has been found to be positively related to all the eight areas of deprivation among girls but only seven areas of deprivation namely- physiological, ecological, social, emotional, economic, educational and parental among boys. Social conversation among boys as well as girls is not related to non-fulfillment of needs, social deprivation and parental deprivation. Emotional deprivation is positively related to social conversation among boys but in the case of girls this relationship is not significant. Dependence among boys is not related to deprivation in the areas of fulfillment of needs, social, educational and parental while in case of girls it is positively related to social, educational and parental deprivation only.

Results of the present study have also indicated that when taken together all the eight areas odf deprivation contribute to more than ten per cent variance in boys' compliance, dependence, ingratiation, social conversation, social passivity, aggression and withdrawal, and girl's power assertion, ingratiation, social passivity, aggression and withdrawal. Concern for others and tolerance among boys are the two least affected social behsviours among boys while in the case of girls concern for others, compliance and social conversation are the three least affected social behaviours.

\section{IMPLICATIONS}

The findings of the present study suggest the need of immediate efforts to be made to reduce exposure to deprivation in physiological, fulfillment of needs, ecological, social, emotional, economic, educational and parental areas. This calls for more thrust on Ayushman Bharat Yojna, Mid Day Meals Scheme, cooperative learning in groups, implementation of programmes related to development of socio-emotional competencies, and personal-social counseling of deprived students. Efforts are also needed for reducing aggression among boys and increasing concern for others among boys

\section{REFERENCES}

Pandey, K. 1987. Deprived students: Cognitive processes, motives and achievement. Kashi: Akhil Bharatiya Vikram Parishad.

Tripathi, L.B. and Misra, G. 1987. Some cognitive processes as fonctions of prolonged deprivation. In K. G. Agarwal (Ed.) Poverty, deprivation and intelligence. New Delhi: Criterion Publishers, 249-266. 